\title{
Effect of low intensity pulse ultrasound on the neutrophil function and epithelial thickness after skin excision in diabetes mellitus type 2 rats' model (an immunohistochemistry study on matrix metalloproteinase-9)
}

\author{
Titis Laraswati, Cahya Y. Hasan, ${ }^{*}$ Bambang Dwirahardjo
}

\begin{abstract}
Objective: To determine the effect of Low Intensity Pulse Ultrasound (LIPUS) on the neutrophil function and epithelial thickness after skin excision in diabetes mellitus type 2 rats'model (an Immunohistochemistry Study on Matrix Metalloproteinase-9).

Material and Methods: Thirty-six Sprague dawley rats were divided into six groups: DM2, DM4, DM7, DML2, DML4, and DML7, each of which consist of 6 rats. Rats that matched the inclusion criteria were made into diabetes mellitus type 2 by injecting Nicotinamide and Streptozotocin. In all rat's excision wound was made with punch biopsy in the back area. DML group received LIPUS therapy in the wound area (frequency: $3 \mathrm{MHz}$, intensity: $0.5 \mathrm{~W} / \mathrm{cm} 2$, duty cycle: $20 \%$, duration: 3 minutes every day) for two days (DML2), four days (DML4) and

seven days (DML7). In the wound tissue an immunohistochemical examination was performed with Polyclonal Antibody MMP-9 to observe MMP-9 expression and and Periodic Acid-Schiff staining to observe epithelial thickness.

Results: Two-Way ANOVA and Post-Hoc LSD test showed lower level of MMP-9 expressions in the DML group than in the DM group, whereas the epithelial thickness in the DML group was found higher than in the DM group. The Pearson test showed a correlation between the level of MMP-9 expressions and epithelial thickness $(p=0.000$; $r=-0.785)$.

Conclusion: LIPUS therapy reduced MMP-9 expression and increases epithelial thickness.
\end{abstract}

Department of Oral and Maxillofacial Surgery, Faculty of Dentistry, Gadjah Mada University, Yogyakarta, Indonesia
*Correspondence to: Cahya Y. Hasan, Department of Oral and Maxillofacial Surgery, Faculty of Dentistry, Gadjah Mada University, Yogyakarta, Indonesia yustisiahasan@ugm.ac.id

Received: 23 January 2020 Revised: 9 April 2020 Accepted: 3 December 2020 Available Online: 1 April 2021

Keywords: Diabetes Mellitus type 2, Epithelial thickness, Low intensity pulse ultrasound (LIPUS), MMP-9 expression

Cite this Article: Laraswati T, Hasan CY, Dwirahardjo B. 2021. Effect of low intensity pulse ultrasound on the neutrophil function and epithelial thickness after skin excision in diabetes mellitus type 2 rats' model (an immunohistochemistry study on matrix metalloproteinase-9). Journal of Dentomaxillofacial Science 6(1): 54-60. D0I: 10.15562/jdmfs.v6i1.1035

\section{Introduction}

Surgical procedures are commonly found in oral and maxillofacial surgery, during which incisions made may cause skin wound. Wound refers to the partial loss or damage of body tissues that requires healing. ${ }^{1}$ Despite that wound healing process can run normally, some factors may inhibit the process, one of which is Diabetes Mellitus (DM), a systemic disease factor. Diabetes mellitus is a disease with metabolic disorders resulted from damaged insulin secretion, insulin action, or both, leading to increased rate of blood plasma glucose. ${ }^{2} \mathrm{DM}$ consists of DM type 1 and DM type 2. DM type 1 is characterized with absolute deficiency of insulin secretion caused by destruction of pancreatic $\beta$ cells, whereas DM type 2 is caused by combined peripheral resistance to insulin action with an inadequate compensatory response to insulin secretion by pancreatic $\beta$ cells (relative insulin deficiency).

Neutrophils are the most abundant cell type among circulating white cells and constitute the first line of host defense against invading pathogens (bacteria, fungi, etc.). ${ }^{3}$ Neutrophils have two main functions such as anti-microbial function and protease function. Activated neutrophils produce a number of proteases which may generate have positive and negative effects on the wound healing process. Excessive amount of proteases in the tissue can result in damaged tissues and prolonged inflammatory processes, damaged collagen deposition, reduced tensile strength of the wound, and delayed epithelialization process. ${ }^{4}$

Matrix Metalloproteinase-9 (MMP-9) is one of the products produced by neutrophils, especially by gelatinase granules (tertiary granules) in the process of neutrophil development (metamyelocyte phase). ${ }^{4} \mathrm{DM}$ conditions can cause impaired neutrophil cell function which causes inadequate migration and chemotaxis of neutrophils into the wound area, later affecting the speed of wound healing. ${ }^{5-8} \mathrm{DM}$ conditions result in a decrease in the process of neutrophil apoptosis, which will have an impact on increasing the secretion of neutrophil granules and increasing the amount of MMP-9 expression. ${ }^{9,10}$ 
The process of wound healing is closely related to that of epithelialization. Epithelialization is defined as a process of covering denuded epithelial surface. The cellular and molecular processes involved in initiation, maintenance, and completion of epithelialization are essential for successful wound closure. Epithelialization is an essential component of wound healing used as a defining parameter of its success. In the absence of epithelialization, a wound cannot be considered healed. Wound healing is condiderably affected by the process of epithelialization in which the faster process of epithelialization leads to faster closure of the wound. Epithelialization is a parameter of successful wound healing, as seen and measured by increased epithelial thickness in wound. ${ }^{11,12}$

Certain therapies can improve wound healing in DM conditions; among others is Low Intensity Pulse Ultrasound (LIPUS), one of the biophysical therapies as an alternative therapy for impaired wound healing on the skin. LIPUS therapy is a device that emits low intensity ultrasonic waves with exposure to broken waves (pulsed) which functions as a non-invasive therapy by flowing micro mechanical pressure energy from ultrasonic waves transcutaneously into biological tissue, the process that will produce biochemical effects in the form of accelerated tissue healing. ${ }^{13}$ The influence of the LIPUS on skin cell is initiated through the acoustic streaming mechanism, which is the physical pressure of the sound waves that produce intra and extracellular ion exchange that will cause changes in cell membrane permeability and result in an increase in cell electrophysiology. ${ }^{14}$

Different biological effects associated with LIPUS therapy have been observed. Previous experimental studies confirmed that LIPUS therapy can reduce the number of neutrophils and inflammatory macrophages on the first day (M1) after wound is made and increase the reparative macrophages (M2) in the transition from the inflammatory response to the repair period of incision wound. ${ }^{15}$ Exposure to LIPUS can reduce the expression of Matrix metalloproteinase -2 and Matrix Metalloproteinase-9 through the PI3aK / AKT pathway in normal rats. ${ }^{16}$ Exposure to LIPUS promotes the proliferation and migration of gingival epithelial cells and accelerates wound healing in soft tissues. ${ }^{17}$ LIPUS waves can affect the epithelialization process through acoustic streaming, non thermal effects. ${ }^{18}$

LIPUS is known to stimulate the production of chemical mediators that activate the proliferation of fibroblasts. ${ }^{19}$ LIPUS effects in the model of epithelial wound repair were also investigated, and found that ultrasonic directly stimulates epithelial cell migration and / or proliferation, thereby increasing wound re-epithelialization. ${ }^{20}$ This study was aimed at determining the effects of Low Intensity Pulse Ultrasound (LIPUS) on the neutrophil function and epithelial thickness after skin excision in diabetes mellitus type 2 rat models.

\section{Material and Methods}

Thirty-six rats that met the inclusion criteria were quarantined for 2 days for adaptation before the study was conducted. Thirty-six Sprague dawley rats were divided into six groups: DM2, DM4, DM7, DML2, DML4, and DML7, each of which consist of 6 rats. Rats were made into DM type 2 by induction or injection of NA (100 mg/kgBW) and STZ $(65 \mathrm{mg} /$ $\mathrm{kgBW})$. Rats were declared to have DM type 2 if blood glucose level was $>200 \mathrm{mg} / \mathrm{dL}$ after induction of NA and STZ on day 5. No food was given to the rats 4 hours prior to the anesthetic administration, then they were anesthetized with intra peritoneal injection of $10 \%$ ketamine $(100 \mathrm{mg} / \mathrm{kg} \mathrm{BW})$ and xylazine $(10 \mathrm{mg} / \mathrm{kg} \mathrm{BW})$, after which the fur was smeared with depilatory cream, continued with marking the treated area using a marker. The rat's back was sterilized with $10 \%$ alcohol solution and $10 \%$ povidone iodine and excision was made with a $5 \mathrm{~mm}$ punch biopsy with subcutaneous depth on it.

The wound area on the back of the rat (DML2, DML4, DML7) was smeared with coupling agent gel first, then given LIPUS therapy with a frequency parameter of $3 \mathrm{MHz}$, intensity $0.5 \mathrm{~W} / \mathrm{cm} 2$, duty cycle $20 \%$, duration of exposure 3 minutes every day. DM 2 and DML 2 groups were decapitated on day 2 after excision, DM 4 and DML 4 groups were decapitated on day 4 after excision, while DM7 and DML7 group were decapitated on day 7. Preparation for the examination of MMP-9 expression and epithelial thickness in accordance with a predetermined pattern after decapitation measures.

Rat skin samples fitting with the pattern to see the MMP-9 expression were put into $10 \%$ formalin buffer solution and taken to the Anatomic Pathology Laboratory of the Faculty of Medicine, Universitas Gadjah Mada to be processed up to the immunohistochemical staining (MMP-9 polyclonal antibody) and PAS staining. With the Optilab camera, microscopic images were taken on the results of the preparation. MMP-9 expression data and epithelial thickness were calculated with Image-J software combined with direct observation by anatomical pathologists figure $1 \mathrm{~A}$ and figure $1 \mathrm{~B}$.

\section{Results}

Body weight measurements were performed at the beginning of the adaptation period before NA and STZ induction (initial BW), day 5 after NA and STZ induction and during excision (BW excision), 
Table 1 Rat Body Weight (BW) during the study

\begin{tabular}{|c|c|c|c|c|c|c|}
\hline $\begin{array}{l}\text { Group of } \\
\operatorname{rats}(n)\end{array}$ & $\begin{array}{c}\text { Initial BW } \\
(x \pm S D)\end{array}$ & $\begin{array}{c}\text { BW excision } \\
(x \pm S D)\end{array}$ & $\begin{array}{c}\text { BW H+2 } \\
(x \pm S D)\end{array}$ & $\begin{array}{c}\text { BW H+4 } \\
(x \pm S D)\end{array}$ & $\begin{array}{c}\text { BW H+7 } \\
(x \pm S D)\end{array}$ & $\mathbf{p}$ \\
\hline DM2(6) & $230.83 \pm 9.0$ & $223.6 \pm 9.5$ & $213.8 \pm 8.04$ & - & - & $0.001^{\star}$ \\
\hline DM4(6) & $224.2 \pm 10.2$ & $218.3 \pm 7.5$ & $212.1 \pm 5.0$ & $211.5 \pm 5.2$ & - & $0.011^{\star}$ \\
\hline DM7(6) & $237.5 \pm 9.4$ & $233.5 \pm 9.5$ & $228.3 \pm 8.8$ & $223.7 \pm 9.5$ & $223.6 \pm 9.6$ & $0.000^{*}$ \\
\hline DML2(6) & $230.8 \pm 9.0$ & $218.3 \pm 7.5$ & $213.8 \pm 8.04$ & - & - & $0.001^{\star}$ \\
\hline DML4(6) & $230.8 \pm 13.9$ & $227.6 \pm 13.9$ & $224.5 \pm 14.2$ & $224.3 \pm 11.08$ & - & $0.009^{\star}$ \\
\hline DML7(6) & $230.8 \pm 9.2$ & $226.8 \pm 9.9$ & $224.3 \pm 7.7$ & $223.8 \pm 9.9$ & $220.3 \pm 9.8$ & $0.004^{*}$ \\
\hline
\end{tabular}

Table 2 Blood Glucose (BG) of rats during the study

\begin{tabular}{|c|c|c|c|c|c|c|}
\hline Group of rats(n) & $\begin{array}{c}\text { Initial BG } \\
(x \pm S D)\end{array}$ & $\begin{array}{c}\text { BG induction } \\
(x \pm S D)\end{array}$ & $\begin{array}{c}\text { BG H+2 } \\
(x \pm S D)\end{array}$ & $\begin{array}{c}\text { BG H+4 } \\
(x \pm S D)\end{array}$ & $\begin{array}{c}\text { BG H+7 } \\
(x \pm S D)\end{array}$ & $\mathbf{p}$ \\
\hline DM2(6) & $108.6 \pm 1.5$ & $312.1 \pm 9.9$ & $325.8 \pm 6.7$ & - & - & $0.00^{*}$ \\
\hline DM4(6) & $107.0 \pm 2.1$ & $307.8 \pm 4.7$ & $323.1 \pm 5.5$ & $336.0 \pm 6.1$ & - & $0.00^{*}$ \\
\hline $\operatorname{DM7}(6)$ & $107.0 \pm 1.7$ & $312.5 \pm 2.5$ & $321.5 \pm 5.4$ & $335.8 \pm 11.5$ & $375.6 \pm 9$ & $0.00^{*}$ \\
\hline DML2(6) & $108.1 \pm 2.8$ & $314.8 \pm 4.9$ & $330.5 \pm 10.3$ & - & - & $0.00^{*}$ \\
\hline DML4(6) & $107.8 \pm 2.14$ & $313.8 \pm 9.8$ & $319.5 \pm 9.7$ & $326.0 \pm 12.1$ & - & $0.00^{*}$ \\
\hline DML7(6) & $109.1 \pm 3.1$ & $308.5 \pm 5.9$ & $317.5 \pm 5.2$ & $326.5 \pm 10.7$ & $384.3 \pm 10$ & $0.00^{*}$ \\
\hline
\end{tabular}

Table 3 Average MMP-9 expression and epithelial thickness between days of observation

\begin{tabular}{|c|c|c|c|c|}
\hline Variable & Group of rats & $\begin{array}{c}\text { Day } 2 \\
\text { (x }\end{array}$ & $\begin{array}{c}\text { Day } 4 \\
\text { (x }\end{array}$ & $\begin{array}{c}\text { Day } 7 \\
\text { (x }\end{array}$ \\
\hline \multirow[t]{2}{*}{ MMP-9 expression } & DM2, DM4, DM7 & $137.38 \pm 18.40$ & $135.56 \pm 18.04$ & $47.56 \pm 8.06$ \\
\hline & DML2, DML4, DML7 & $84.28 \pm 8.08$ & $65.06 \pm 7.14$ & $30.23 \pm 4.88$ \\
\hline \multirow[t]{2}{*}{ Epithelial thickness } & DM2, DM4, DM7 & $0.15 \pm 0.02$ & $0.64 \pm 0.18$ & $0.81 \pm 0.02$ \\
\hline & $\overline{\text { DML2, DML4, DML7 }}$ & $0.68 \pm 0.04$ & $1.11 \pm 0.11$ & $1.56 \pm 0.13$ \\
\hline
\end{tabular}

\section{Table 4 Two Ways ANOVA statistical test (the comparison of MMP-9} expression and epithelial thickness)

\begin{tabular}{lcc}
\hline Variable & $\begin{array}{c}\text { p value MMP-9 } \\
\text { expression }\end{array}$ & $\begin{array}{c}\text { p value epithelial } \\
\text { thickness }\end{array}$ \\
\hline Group (DM dan DML) & $0.000^{*}$ & $0.000^{*}$ \\
Days (2, 4 and 7) & $0.000^{*}$ & $0.000^{*}$ \\
Correlation between & $0.000^{*}$ & $0.009^{*}$ \\
group and days & & \\
\hline
\end{tabular}
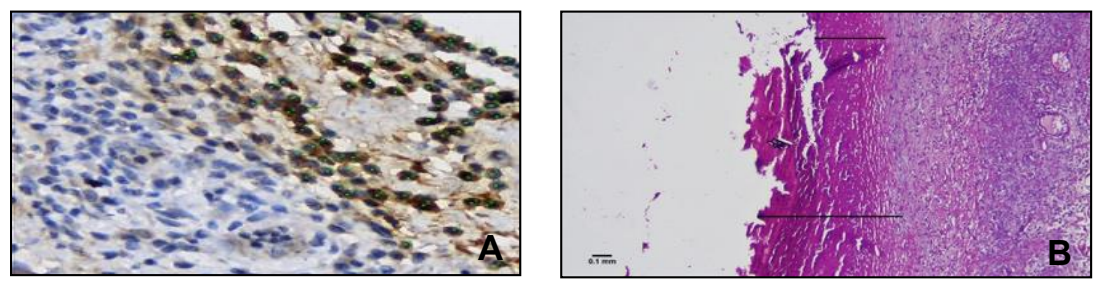

Figure 1 A. MMP-9 expression (brown colored) with MMP-9 IHC staining, B. Epithelial thickness with Periodic Acid Schiff staining

day 2 after excision (BW $\mathrm{H}+2)$, day 4 after excision (BW $\mathrm{H}+4)$, and day 7 after excision (BW $\mathrm{H}+7$ ). The rat body weight in all groups met the inclusion criteria (200-250 grams) until the decapitation, none belonged to the exclusion criteria. Results of weight measurements between days of observation table 1 showed that all subjects experienced significant weight loss $(\mathrm{p}<0.05)$ in all groups. Weight loss began on day 5 after induction of NA and STZ, then continued to decrease up to the decapitation time.

The observations result of blood glucose level table 2 on the initial day of adaptation into the cage entirely indicated that the blood glucose level of normal rats in all groups was less than $200 \mathrm{mg} / \mathrm{dL}$. Increased level of blood glucose began to occur on day 5 after induction of NA and STZ, increasing on day 2 after excision, then continued to increase until day 4 and 7 following excision. Blood glucose level of NA and STZ after induction in all groups until the average decapitation time reached more than $200 \mathrm{mg} / \mathrm{dL}$ (met the inclusion criteria). Increased blood glucose level in all groups of rats showed a significant difference $(\mathrm{p}<0.05)$.

The highest amount of MMP-9 expression was found in the DM 2 group $(137.38 \pm 18.40)$, while the lowest was the DML 7 group $(30.23 \pm 4.88)$ table 3 , 

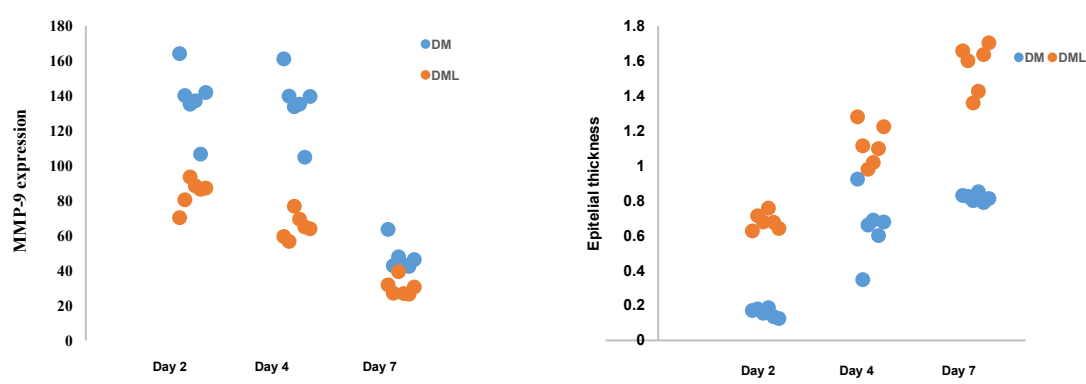

Figure 2 A. Graph of average MMP-9 expression in DM and DML groups between days of observation, B. Graph of average epithelial thickness in DM and DML groups between days of observation
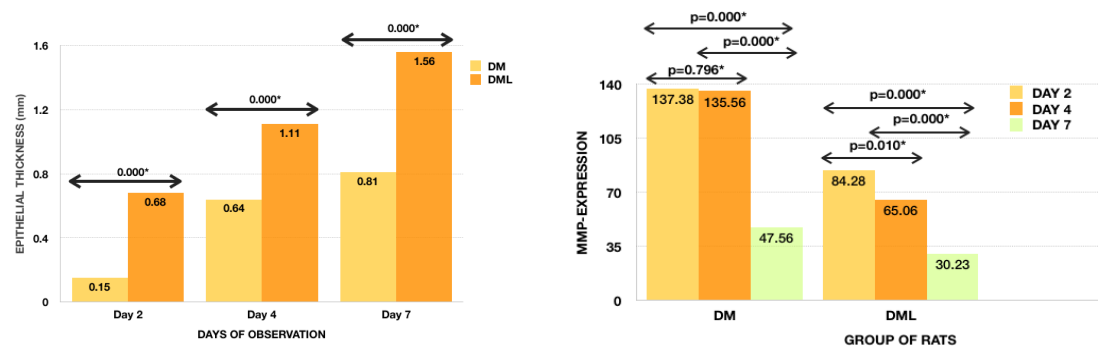

Figure 3 A. Comparison of MMP-9 expression between groups ( $\mathrm{p}=$ Post Hoc LSD test), B. Comparison of MMP-9 expression between days of observation ( $\mathrm{p}=$ Post Hoc LSD test)
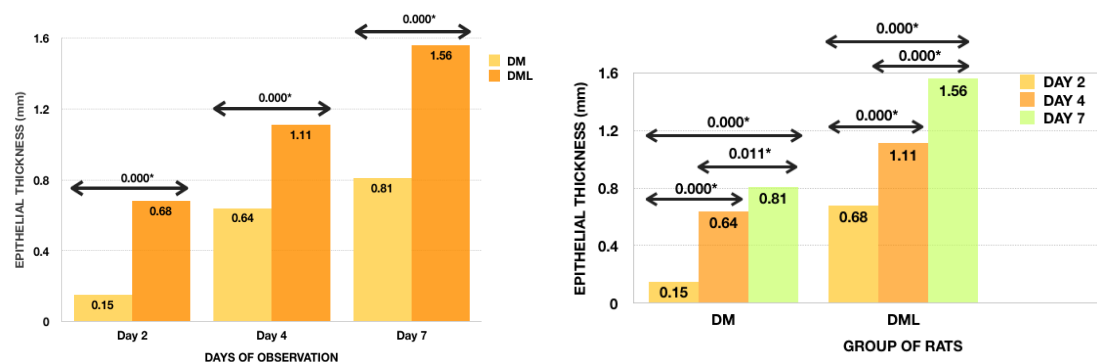

Figure 4 A. Comparison of epithelial thickness between groups $(p=$ Post- Hoc LSD test), B. Comparison of epithelial thickness between days of observation ( $p=$ Post-Hoc LSD test)

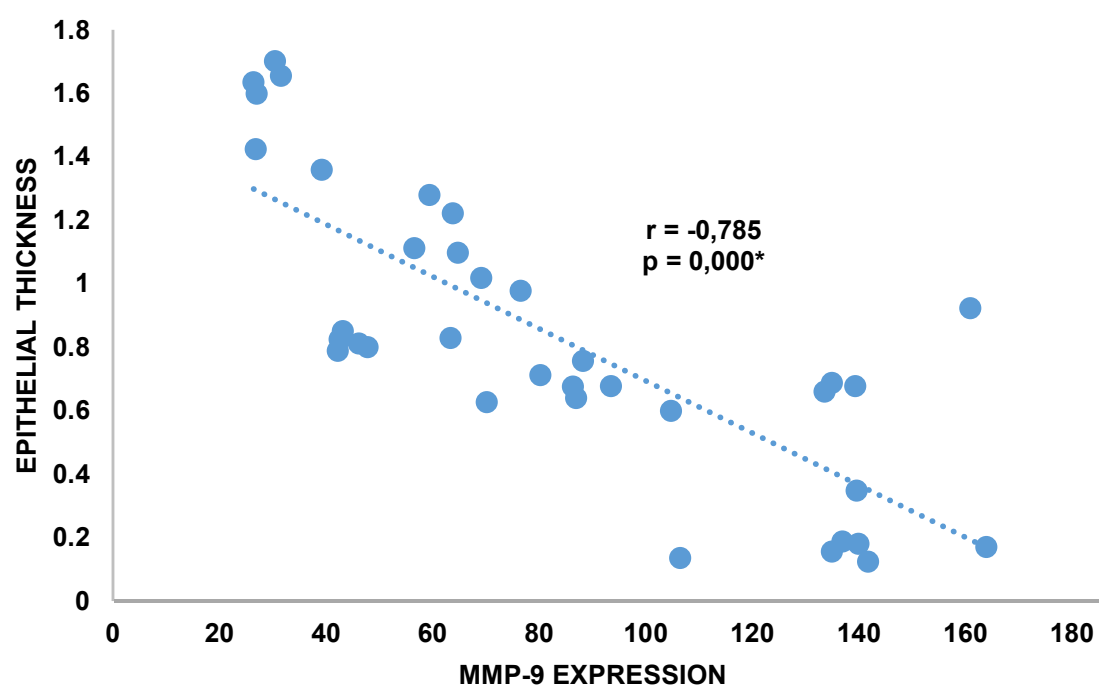

Figure 5 Pearson's correlation test between the amount of MMP-9 expression and epithelial thickness in the DM and DML groups figure $2 \mathrm{~A}$ and figure $2 \mathrm{~B}$. Figure $3 \mathrm{~A}$ shows that the DM rat group administered with LIPUS therapy had a lower MMP-9 expression compared to the DM rat group without LIPUS therapy figure 3B. The highest epithelial thickness was seen in the DML 7 group (1.56 \pm 0.13$)$, while the lowest epithelial thickness was in the DM 2 group $(0.15 \pm 0.02)$. Figure 4 shows that the DM rat group treated with LIPUS had thicker epithelial thickness compared to the DM rat group not receiving LIPUS therapy.

Two-Way ANOVA statistical test table 4 shows a significant difference in the variable of MMP-9 expression and epithelial thickness both between groups and between days of observation with a value of $\mathrm{p}=0.000(\mathrm{p}<0.05)$. The correlation between groups and showed a significant difference $0.000(\mathrm{p}<0.05)$.

The results of the Post- Hoc LSD test showed a significant difference $(\mathrm{p}<0.05)$ on the variable of amount of MMP- 9 expression between groups figure $4 \mathrm{~A}$ and between days of observation figure 4B. The results of the Post-Hoc LSD test on the variable of epithelial thickness showed a significant difference $(\mathrm{p}<0.05)$ between groups. Pearson's correlation test was performed to determine the correlation between the amount of MMP-9 expression and epithelial thickness. Figure 5 shows a correlation between the amount of MMP-9 expression and epithelial thickness with a $p$ value of significance of $0.000(p<0.05)$, while the correlation coefficient $(\mathrm{r}$ ) obtained a value of -0.785 (negative) meaning that lower amount of MMP-9 expression leads to higher epithelial thickness. Conversely, higher amount of MMP-9 expression suggests lower epithelial thickness.

\section{Discussion}

Low Intensity Pulse Ultrasound (LIPUS) therapy is a well-developing breakthrough as a wound healing therapy. LIPUS therapy has thermal and non thermal effects. Non thermal effects of LIPUS on the skin include mechanical effects such as cavitation, acoustic streaming and micromassage. The three will modulate cell biochemistry, stimulate cell viability and tissue repair, may affect the structure, function and permeability of cell membranes, which will cause the movement of intra cellular and extra cellular cells to stimulate anti inflammatory molecules towards cells to increase, resulting in increased function of inflammatory cell proteases. Low Intensity Pulse Ultrasound (LIPUS) therapy can penetrate and reach the deepest tissue of the wound..$^{21}$

This study was conducted to determine the effects of LIPUS on neutrophil function and epithelial thickness after skin excision in Diabetes Mellitus 
type 2 rat models. The neutrophil protease function was observed. Activated neutrophils produce a number of proteases which can have positive and negative effects on the wound healing process. Neutrophil-derived proteases help eliminate and degrade microbes and break down the components of the extracellular matrix. Excessive number of proteases in the tissue can cause tissue damage and prolonged inflammatory processes, damaged collagen deposition, reduced tensile strength of the wound, and delayed epithelialization process. ${ }^{4}$

All subjects experienced significant weight loss in all groups resulted from the effects of hyperglycemia caused by insulin deficiency. Changes in fat and protein metabolism in muscles occurred and was followed by an average weight loss of $25 \%$ and $14 \%$ of initial body weight after induction of NA and STZ. ${ }^{22}$ Hyperglycemia level in patients with DM cannot be optimally utilized to form energy. As a result, considerable amount of glucose is wasted in the urine causing muscle mass and adipose continue for use to fulfill energy.

Blood glucose level of DM type 2 rats in this study increased to more than $300 \mathrm{mg} / \mathrm{dL}$, which began on day 5 after induction of NA and STZ. Increased level of blood glucose is caused by the effects of STZ induction which damage pancreatic beta-langerhans cell and has a direct impact on impaired insulin secretion. Insulin is an anabolic hormone that is needed in the uptake of glucose and amino acids by peripheral tissues. ${ }^{23} \mathrm{NA}$ induction carried out 15 minutes prior to STZ induction was proven to control the blood glucose level in rats to maintain the steady level of increase.

The group administered with LIPUS therapy had the lowest amount of MMP-9 expression when compared to the DM group without LIPUS therapy. The results showed that the amount of MMP-9 expression in the DML2 group was 38,68\% lower than the DM2 group, the amount of MMP-9 expression in the DML4 group was 52,20\% lower than the DM4 group, the amount of MMP-9 expression the DML7 group was $37,5 \%$ lower than the DM7 group. The DM group treated with LIPUS for 7 days (DML7) had the lowest amount of expression compared to all groups. This proves that the longer administration of LIPUS therapy increases the process of neutrophil apoptosis more effectively resulting in decreased amount of MMP-9 expression. Decreased amount of MMP-9 expression caused by a decrease in the number of neutrophil cells and granule secretion in the group treated with LIPUS (DML2, DML4 and DML7) in this study correspond to the previous study conducted by Da Silva Junior et al (2017) who examines LIPUS effects against inflammatory cells in muscle tissues of normal lab rats after cryo injury treatment. The study shows that LIPUS therapy can reduce the number of neutrophils and inflammatory macrophages on the first day (M1) after wound was made and increase emerging reparative macrophages (M2) in the transition from the inflammatory response to the repair period in incision wound. One day after cryo injury, the number of neutrophils in the group treated with LIPUS was significantly lower than in the control group $(\mathrm{p}=0.001) .{ }^{15}$

The decrease in the amount of MMP-9 expressions in this study is consistent with the study of Leng et al (2018) which also states that LIPUS exposure can reduce the expression of Matrix metalloproteinase-2 and Matrix Metalloproteinase-9 through the PI3AK/AKT pathway in normal rats. Relative cell migration in the group receiving LIPUS therapy was significantly higher than in the control group $(\mathrm{p}<0.05)$. Protein expression associated with cell migration was also evaluated. The expression levels of MMP-2 and MMP-9 were significantly reduced by LIPUS stimulation compared to the control group $(\mathrm{p}<0.01){ }^{16}$

Compared with several other studies, the results of this study showed the same thing that is a decrease in the number of inflammatory cells. The effects of ultrasonic waves on macrophages of the J774A rat models in phagocytosis of Escherichia Coli bacteria E. Coli bacteria in rats stimulated with ultrasonic waves for 20 minutes showed maximum phagocytosis when compared to the control group. ${ }^{24}$ The study of Freitas et al. ${ }^{25}$ also found that LIPUS therapy $\left(0.5,1.2 \mathrm{~W} / \mathrm{cm}^{2}\right.$, given for 12 hours, 1,3 and 5 days) in the torn gastrocnemius muscle of Wistar rats caused a decrease in ROS production and showed the lower number of neutrophil cells and M1 macrophages. ${ }^{25} \mathrm{~A}$ study by Renno et al. ${ }^{26}$ observes that LIPUS $\left(1.5 \mathrm{MHz}, 30 \mathrm{~W} / \mathrm{cm}^{2}\right)$ given to the anterior tibia muscle of rats previously received cryo injury treatment was able to reduce the intensity of the inflammatory process when compared with untreated injured experimental animals. ${ }^{26} \mathrm{Shu}$ et al. ${ }^{27}$ also examines the effects of LIPUS ( $3 \mathrm{MHz}$, $0.25 \mathrm{~W} / \mathrm{cm} 2,0.5 \mathrm{~W} / \mathrm{cm}^{2}$ and $0.75 \mathrm{~W} / \mathrm{cm}^{2}$ ) on the repair process in rats with gastrocnemius muscle injury. ${ }^{27}$ Researchers reported a reduced inflammatory process with a lower number of inflammatory cells after 4 and 7 days in all groups treated with LIPUS when compared to groups receiving no LIPUS treatment.

Epithelial thickness in the group treated with LIPUS was higher than in the group without LIPUS therapy. The epithelial thickness in the DM7 group increased by $66 \%$, whereas in the DML7 group it increased by $88 \%$. The average epithelial thickness in the DML group was almost 2 times higher 
than that of the DM group receiving no LIPUS treatment. Increased epithelial thickness occurs because LIPUS effects can increase the production of fibroblast cell. This finding is consistent with Zhou et al. ${ }^{28}$ study which shows that Low Intensity Pulsed Ultrasound treatment is able to promote DNA synthesis in quiescent primary skin fibroblasts. Daily repeated ultrasound stimulation, which resembles the clinical schedule, substantially increases cell numbers. These experiments demonstrate that a physical stimulus, acoustic pulsed energy, can promote cell proliferation, which is a prerequisite of wound healing. ${ }^{28}$

The increase in epithelial thickness that occurred in the DML group in this study was also caused by an increase in growth factors, as found in the study of Shindo et al (2016) which examines the effects of LIPUS on the repair of left venticular tissue in rat models with acute myocardial infarction in which the heart was treated with LIPUS 3 times in the first week (day 1, 3, and 5). ${ }^{18}$ LIPUS waves can reduce mortality rate and improve post-myocardial infarction in rat left venticular by increasing the expression of growth factors in vascular endothelial cells, increasing NOS, phosphorylated ERK, and phosphorylated AKT in the area of initial infarction after acute myocardial infarction, which leads to an increase in the process of angiogenesis.

This study proves that Low Intensity Pulse Ultrasound (LIPUS) therapy with a frequency parameter of $3 \mathrm{MHz}$, intensity of $0.5 \mathrm{~W} / \mathrm{cm}^{2}$, duty cycle $20 \%$, exposed for 3 minutes every day for 7 days, can significantly reduce MMP-9 expression and increase the epithelial thickness after skin excision of Diabetes Mellitus type 2 rat models. ${ }^{29}$

\section{Conclusion}

Low Intensity Pulse Ultrasound (LIPUS) therapy with a frequency parameter of $3 \mathrm{MHz}$, intensity of $0.5 \mathrm{~W} / \mathrm{cm}^{2}$, duty cycle $20 \%$, exposed for 3 minutes administered on a daily basis, can significantly reduce MMP-9 expression ( $\mathrm{p}$ value $=0.000$ ) and increase epithelial thickness $(\mathrm{p}=0.000)$ after skin excision of Diabetes Mellitus type 2 rat models.

\section{Acknowledgment}

This undergraduated thesis is submitted as the final requirement in accomplishing undergraduate degree at Department of Oral and Maxillofacial Surgery, Faculty of Dentistry, Gadjah Mada University, Yogyakarta. The researcher expresses the highest gratitude to God for blessing and mercy to complete this undergraduate thesis. The researcher gratefully thanks to our supervisor,
Cahya Yustisia Hasan, SpBMM and Bambang Dwi Rahardjo, SpBMM for supervision, advice and correction until the completion of this thesis.

\section{Conflict of Interest}

The authors report no conflict of interest.

\section{References}

1. Sjamsuhidajat R, De-Jong W. Surgical Textbook. 3rd ed. Penerbit Buku Kedokteran EGC; Jakarta: 2010. p. 67. (In Indonesia)

2. Valero AM, Garcia JCF, Ballester AH, et al. Effects of diabetes on the osseointegration of dental implants. Med Oral Patol Oral Cir Bucal 2007;12: 38- 43.

3. Luo HR and Loison F. Constitutive neutrophil apoptosis: mechanisms and regulation. Am J Hematol 2008;83: 288- 295.

4. Wilgus TA, Roy S, Jodi C, et al. Neutrophils and wound repair: positive actions and negative reactions. Adv Wound Care 2013;2: 379- 388 .

5. Blakytny R, Jude E. The Molecular biology of chronic wounds and delayed healing in diabetes. Diabet Med 2006;23: 594- 608 .

6. Volmer TM, Lobmann R. Neuropathy and diabetic foot syndrome. Int J Mol Sci 2016;17: 1- 11.

7. Tuhin RH, Begum MM, Rahman S, et al. Wound healing effect of euphorbia hirta linn. (euphorbiaceae) in alloxan induced diabetic rats. BMC Complement and Alternative Medicine 2017;17: 1- 14

8. Kintoko, Karimatulhajj H, Elfasyari TY, et al. Effect of diabetes condition on topical treatment of binahong leaf fraction in wound healing process. Trad Med J 2017;22: 103- 110.

9. Loureiro TCA, Munhoz CD, Martins JO, et al. Neutrophil function and metabolism in individuals with diabetes mellitus. Braz J Med Biol Res 2007;40: 1037- 1044.

10. Pithon-Curi TC, Schumacher RI, Freitas JJ, et al. Glutamine delays spontaneous apoptosis in neutrophils. Am J Physiol Cell Physiol, 2003; 284: C1355- C1361.

11. Pastar I, Stojadinovic O, Yin NC, et al. Epithelialization in wound healing: a comprehensive review. Adv Wound Care 2013;3: 445- 464

12. Nooh N, Graves DT. Healing is delayed in oral compared to dermal excisional wounds. J Periodontol 2003;74: 242- 246.

13. Rousseau G, Blouin A, Monchalin JP. Non-contact photo acoustic tomography and ultrasonography for tissue imaging. Biomed Opt Expres 2012;3: 16- 25.

14. Lou S, Liv H, Li Z, et al. The effects of low intensity pulsed ultrasound on fresh fracture. Medicine 2017;96: e8181.

15. Da-Silva-Junior EM, Mesquita-Ferrari RA, Franca CM, et al. Modulating effect of low intensity pulsed ultrasound on the phenotype of inflammatory cells. Biomed Pharmacother 2017;96: 1- 7.

16. Leng X, Shang J, Gao D, et al. Low intensity pulsed ultrasound promotes proliferation and migration of hacat kera-tinocytes through the PI3K/AKT and JNK Pathways. Braz J Med Biol Res 2018;51: e7862.

17. Iwanabe Y, Masaki C, Tamura A, et al. The effect of low intensity pulsed ultrasound on wound healing using scratch assay in epithelial cells. J Prostho Res 2016;60: 308- 314 .

18. Shindo $\mathrm{T}$, Ito $\mathrm{K}$, Ogata $\mathrm{T}$, et al. Low intensity pulsed ultrasound enhances angiogenesis and ameliorates left ventricular dysfunction in a mouse model of acute myocardial infarction. Arterioscler Thromb Vasc Biol 2015; 36:1220- 1229 .

19. Piedade MC, Galhardo MS, Battlehner CN, et al. Effect of ultrasound therapy on the repair of gastrocnemius muscle injury in rats. J Ultrasonics 2008;48: 403- 411. 
20. Hill GE, Fenwick S, Matthews BJ, et al. The effect of low intensity pulsed ultrasound on repair of epithelial cell monolayers in vitro. Ultrasound Med Biol 2005;1: 1701- 1706.

21. Tian S, Li M, Dong F, et al. The role of low intensity pulsed ultrasound on bone and soft tissue healing. Int J Clin Exp Med 2016;9: 12450- 12456.

22. Nakhaee A, Bokaeian M, Saravani M, et al. Attenuation of oxidative stress in streptozotocin-induced diabetic rats by eucalyptus globulus. Indian J Clin Biochem 2009;24: 419- 425.

23. Kiran G, Nandini CD, Ramesh HP, et al. Progression of early phasediabetic nephropathy in streptozotocin induced diabetic rats: evaluation of various kidney related parameters. Ind J Exp Biol 2012;50: 133- 140.

24. Zhou S, Bachem MG, Seufferlein T, et al. Low intensity pulsed ultrasound accelerates macrophage phagocytosis by a pathway that requires actin polymerization Rho Src/ MAPKs activity. Cell Signal 2008;20: 695- 704.

25. Freitas LBS, Freitas TP, Rocha LG, et al. Effect of therapeutic pulsed ultrasound on parameters of oxidative. Cell Biol Int 2007;31: 482- 488 .
26. Renno ACM, Toma RL, Feitosa SM, et al. Comparative effects of low intensity pulsed ultrasound and low level laser therapy on injured skeletal muscle. Photomed Laser Surg 2011;29: 5- 10.

27. Shu B, Yang Z, Li X, et al. Effect of different pulsed ultrasound on the restoration of rat skeletal muscle contusion. Cell Biochem Biophys 2012;62: 329- 336.

28. Zhou S, Schmelz A, Seufferlein T, et al. Molecular mechanisms of low intensity pulsed ultrasound in human skin fibroblasts. J Biol Chem 2004;279: 54463-54469.

29. Nainggolan LI, Gunasagaran L. Prevalence of alveolar bone deffect pattern in periodontitis patients with diabetes mellitus using bitewing radiography. J Dentomaxillofac Sci 2018;3: 88-90.

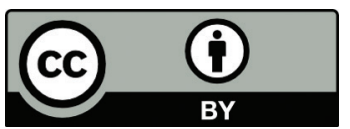

This work is licensed under a Creative Commons Attribution 